\title{
REGIONALIZAÇÃO E REDE URBANA ${ }^{1}$
}

\author{
Michel Rochefort ${ }^{\star}$
}

A idéia central desta palestra é discutir um pouco a relação entre Geografia e Planejamento, e, nesse campo muito discutido da regionalização, ver um pouco as distorções entre a análise geográfica dos problemas de desequilíbrios regionais e as tentativas, muitas vezes sem sucesso, do planejamento para reduzir esses desequilíbrios regionais.

Redução das disparidades regionais e descentralização inter-regional das indústrias têm aqui o mesmo significado de regionalização.

De um modo geral, em quase todos os países existem serviços de planejamento que são denominados de setor de regionalização. São os esforços de intervenção do poder público na organização do espaço nacional. Há 20 ou 25 anos se fala em regionalização na Argentina. Após a independência dos países da África Tropical, por volta de 1960, também se começou a falar de regionalização na Costa do Marfim e no Senegal. Há muito tempo o Brasil tem uma política de descentralização inter-regional das indústrias, apesar de os resultados não terem sido importantes.

Assim, nota-se que o problema da regionalização é bastante evidente nos países em desenvolvimento, no setor de planejamento. Entretanto, a palavra regionalização é utilizada com sentido diferente segundo os serviços.

Para alguns planejadores, regionalização é somente uma reorganização administrativa do espaço nacional. Quando se considera que a divisão antiga não está boa, procura-se fazer uma reorganização adminis- trativa. Para outros, a regionalização tem um sentido mais amplo. Regionalização é um esforço para diminuir as disparidades entre as regiões e tentar reequilibrar o espaço nacional, seja do ponto de vista do fator de desenvolvimento, seja do ponto de vista ligado à distribuição da renda, etc.

Essa intenção de regionalizar, no sentido de reequilibrar o espaço, é ligada ao fato de que os espaços de um país em desenvolvimento são espaços muito desequilibrados do ponto de vista da localização dos fatores de desenvolvimento e da localização da renda familiar.

A intenção é boa, porém os resultados alcançados são muito precários. É muito difícil dizer se é bom ou não.

Mesmo com um programa, os desequilíbrios regionais ficam muito agudos, e por isso não sei dizer se sem o programa seria melhor. O problema não foi resolvido e os desequilíbrios regionais ainda são importantes. Geram ainda duas coisas do ponto de vista teórico que podem parecer prejudiciais ao desenvolvimento do país em zonas de pouco desenvolvimento das atividades de produção do setor moderno no espaço e sobretudo zonas de pobreza, como no Nordeste do Brasil e no Norte da Costa do Marfim, para tentar comparar países diferentes.

Então, quando se trata de ver de um lado a intenção do planejamento e do outro lado as dificuldades de realização do geógrafo pode-se perguntar: será que analisando a realidade, as condições, as causas e aspectos dos desequilíbrios regionais nós vamos encon-

\footnotetext{
${ }^{1}$ publicada originalmente em 1982 no número 4 do Caderno Prudentino de Geografia.

* Professor do Instituto de Geografia da Universidade de Paris I - Pantheon - Sorbonne.
} 
trar uma explicação da diferença entre a intenção e a realização do planejamento?

Bem, podemos perguntar se o planejamento tinha realmente intenção de modificar as disparidades regionais ou se na verdade o programa era só para falar. Isto é, uma análise mais teórica do papel do planejamento territorial nos países do Terceiro Mundo em geral e talvez em todos os países do mundo.

Vamos tentar ver um pouco os aspectos e os mecanismos que vão gerar essas diferenças regionais nos países em desenvolvimento. Podemos dizer que há três critérios que podem ser estudados para uma primeira descrição dos desequilíbrios regionais e para ver a oposição entre as regiões de aspectos econômicos diferentes.

Tem a repartição da indústria, que em todos os países, mas muito mais em países em desenvolvimento, é uma repartição que vai mostrar uma concentração da indústria em alguns pontos do espaço nacional, muito mais em uma região desenvolvida que em outras, então, quaisquer que sejam as diferenças nos países desenvolvidos, é mais aguda esta oposição nos países em desenvolvimento.

Nós podemos aceitar como primeira linha de análise, que a presença da indústria é um fator de multiplicação dos empregos, o que não quer dizer fator de desenvolvimento, mas que a localização de uma indústria vai provocar alguns efeitos multiplicadores sobre as outras atividades de uma região. Então, desse ponto de vista, podemos aceitar que a presença da indústria é um fator de aumento do número de empregos, de crescimento das atividades terciárias para satisfazer as necessidades da nova população e também, de uma certa maneira, um fator de crescimento e modificação da economia agrícola por razões de concentração de mercados de produtos alimentícios em cidades que vão crescer por razões do crescimento industrial.

Essa repartição desigual das indústrias nos países em desenvolvimento é um fator de desequilíbrio regional porque é um fator de concentração de outras atividades na zona em que se concentra a indústria.

Um outro critério que vai permitir ver essa oposição entre as regiões é o critério do chamado terciário superior, quer dizer, de toda parte das atividades terciárias que são as atividades de comando das sedes das empresas industriais, e das empresas comerciais ou sedes de direção dos bancos, que são todas as profissões ligadas a essa atividade de decisão muito importante no país, em que há uma privatização do poder de decisão, o que naturalmente ocorre dentro do sistema de propriedade particular do poder de decisão.

Todo sistema de planificação chamado socialista é bastante diferente, pois o papel do Estado se encontra em todos os espaços.
Eu quero analisar os problemas de desequilíbrios regionais e de tentativas de resolver esses problemas no sistema capitalista, visto que estou dentro do sistema capitalista.

Dentro do sistema, vamos ver qual o papel do planejamento e quais são as dificuldades e possibilidades, os interesses do planejamento quando se trata do problema da regionalização.

O segundo fator bastante importante dos desequilíbrios regionais é o problema da localização do terciário superior, quer dizer, as atividades que representam as atividades de decisão que é toda a parte privada do funcionamento do sistema (sic). Quer sejam as empresas de produção, os bancos, os serviços, etc.

$E$ vamos verificar que esse terciário superior ainda é concentrado numa região, talvez numa cidade e nos arredores de uma cidade que tenha a indústria.

Assim, vai haver uma diferença bastante importante entre as zonas que vão concentrar todas as atividades de decisão, todo esse terciário superior, e o resto do espaço "comandado", quer dizer, o espaço que recebe as decisões da região onde se encontram e se concentram as atividades de decisão.

O terceiro critério que vai permitir visualizar esses desequilíbrios regionais são os fatores de repartição da renda, naturalmente da renda média, porque eu vou dizer que a região de concentração da indústria ou de concentração do terciário superior é uma região de ricos, o que seria um erro fundamental porque elas não funcionam sem os pobres.

Dentro desse conjunto geral de pobreza, quer dizer, de uma percentagem importante da população que é de baixa renda, tem o problema de localização dos ricos. Naturalmente, a maior parte das categorias de população de maior renda vai se encontrar também nas regiões onde a concentração da indústria e do terciário superior se dão. Portanto, um desequilíbrio social entre regiões que têm a concentração de indústrias e as que não têm.

$\mathrm{E}$, naturalmente, vai aparecer um quarto critério que vai mostrar essa diferença entre as regiões, esses desequilíbrios regionais, que é o critério de serviços não do terciário chamado superior do ponto de vista das chamadas atividades de decisões, mas dos serviços de nível superior, dos serviços de luxo.

Os serviços mais sofisticados que são todos os serviços de saúde mais especializados, todos os serviços de instrução de alto nível, de pesquisa, serviços comerciais de luxo, de produtos de grande raridade, etc.

Então, como é que vamos ver o espaço desses países em desenvolvimento utilizando esses quatro critérios para fazer uma diferenciação entre as regiões e 
ver então esses chamados desequilíbrios regionais ou disparidades regionais?

Naturalmente há países bastante simples e países bastante complicados. O Brasil é um país bastante complicado porque a evolução do Brasil foge do modelo simples de países chamados em desenvolvimento por razões várias. Para facilitar a demonstração vamos falar primeiro das coisas simples. E as coisas simples se colocam nos países que podemos chamar de subdesenvolvidos, onde as tentativas de desenvolvimento estão começando somente agora, como é o caso dos países da África Tropical, por razões da história desses países.

Tomando o exemplo da Costa do Marfim, vamos ver um modelo quase perfeito do ponto de vista da demonstração dos desequilíbrios regionais e dos tipos de regiões e da titulação entre os tipos de regiões para um funcionamento da economia do país dentro do espaço nacional. Porque é um país que até 1960 era de economia totalmente chamada de exportação de produtos de base. Era uma colônia da França. Era interesse da França manter uma economia de exportação de produtos brutos a serviço da indústria e naturalmente da concentração do valor agregado na França com relação aos produtos brutos que vinham da Costa do Marfim.

Esse país era de exportação de produtos brutos, quer sejam produtos de economia agrícola, quer sejam produtos do subsolo.

E para o modelo, e isso que é importante, tinha só um porto equipado para a concentração, drenagem e exportação desses produtos.

Então como se organiza o espaço?

De uma maneira bastante simples. De um lado a zona de exportação, que é o porto, quer dizer, a cidade de Abidjam. Em Abidjam chegavam os produtos brutos para a exportação. E esses produtos dependiam de muitos fatores do meio natural, do tipo de população. Tinham algumas zonas de produção de café, zonas de produção de café e cacau, zonas de produção de algodão, zonas de produção de óleo de palmeira, etc.

Havia uma diferenciação regional e havia uma zona ao norte onde existiam poucas atividades de exportação e sobretudo uma sobrevivência de uma economia de agricultura de subsistência.

Havia ainda zonas de culturas tradicionais das aldeias da África com agricultura comunitária para a sobrevivência do grupo humano. Então o sistema regional estava bastante claro nesta época: de um lado o porto e a grande cidade onde se concentravam não as indústrias, porque não havia indústrias, mas as atividades comerciais de exportação, sedes das representações das grandes empresas de "import - export", onde se encontravam os bancos e o poder público, quer dizer, o poder francês e o poder intermediário do povo da Costa do Marfim, onde se encontrava afinal de contas toda a parte rica da população (quer seja a população francesa, quer seja a população intermediária entre os franceses) e o resto do espaço onde se encontravam os serviços.

Fora dessa área central existiam somente as regiões diferentes em função do tipo de economia primária. Nesta região de economia primária existia um certo comércio em função do fato de que a produção estava ligada ao café e ao cacau, o que permitia um certo aumento do nível de vida do camponês africano, apesar dos preços baixos pagos por esses produtos.

Após 1960, inicia-se a segunda fase da economia desses países. E isso com a industrialização ligada à aplicação de capitais vindos de fora. É uma industrialização ligada ao capital francês, ao capital americano, para utilizar as condições maiores de rentabilidade da região. Essa indústria vai ser de utilização de matéria prima local. Uma certa indústria de utilização do poder de consumo, porque, mesmo pobre, tem um certo poder de consumo de sapatos, de tecidos, etc.

Existe também uma indústria interessante de se estudar que é a indústria que utiliza uma matéria-prima que vem de fora e que vai exportar um produto acabado, que está lá somente por razões de custo muito baixo de mão-de-obra. Em função dessa industrialização vai começar a mobilização da força de trabalho.

Isto porque cerca de $90 \%$ da produção industrial vão se localizar em Abidjam e arredores. Abidjam é o único local que tem condições de funcionamento de uma indústria moderna e onde já estão instalados os bancos, os profissionais técnicos, os transportes modernos, água, eletricidade, etc. Abidjam é a única região a oferecer estas condições. Na região de Abidjam, a indústria vai se localizar a 10, 15, 20 e 30 quilômetros, utilizando algumas pequenas cidades.

Assim, vai haver uma drenagem da força de trabalho de outras regiões para a área de Abidjam, principalmente do norte.

São migrações muito amplas que vão fazer com que a população, ainda em economia de subsistência, em extrema pobreza, comece a ser atraída pelas possibilidades de emprego de Abidjam.

Assim, vai aparecer o modelo atual, com uma região de concentração do setor moderno industrial, terciário, e capital política da Costa do Marfim, uma região de economia primária que são as velhas regiões de drenagem da economia de exportação de produtos de base que ainda restam, isto porque à industrialização se soma a permanência da economia de exportação de produtos brutos, e uma região um pouco desligada do funcionamento global da economia moderna, que 
é a região de auto-subsistência, a que se soma uma região de reserva de força de trabalho para a região central.

E assim vamos ter um modelo quase perfeito, de simples funcionamento de uma economia moderna capitalista, dominada, de um país em desenvolvimento com a influência do passado de subdesenvolvimento. Vamos ver o funcionamento de uma região central onde há a concentração do setor moderno, da indústria, do terciário superior, das riquezas, e demais regiões de economia primária de produtos brutos, com algumas diferenças em função do tipo da economia primária e da possibilidade de a população produtiva guardar uma parte do valor global da produção, e a famosa região de reserva de mão de obra. E, para finalizar, há a região Sudeste, que foi até há pouco tempo uma área de reserva de espaço.

Então, temos uma divisão do espaço que é a estrutura do espaço ao serviço de funcionamento do sistema econômico. Podemos dizer que é a tradução dentro do espaço, da estrutura do sistema econômico e que alguns vão chamar de estratégia.

Estratégia do capitalismo é uma palavra um pouco sem sentido. É o resultado das várias estratégias dos empresários que são responsáveis pelo sistema de funcionamento do capitalismo.

É o resultado de todas as estratégias dos empresários de localizar a indústria na região de Abidjam e de utilizar todas as regiões de economias primárias para a famosa drenagem da economia de exportação de produtos brutos.

Então vamos ver que estas disparidades regionais muito agudas num país como a Costa do Marfim são o resultado imediato do sistema que se está fazendo, que é o sistema que podemos chamar de capitalista dominado, capitalista com influência dos grandes focos do capitalismo internacional.

Em outros países vamos ver vários fatores de complicação do modelo. Esse modelo quase perfeito da África Tropical, nos países mais evoluídos tem as mesmas tendências, mas com um pouco mais de dificuldade de sistematização.

Quais os fatores de complicação?

Um dos maiores fatores de complicação do modelo é o problema da estrutura do espaço na época da economia de exportação de produtos brutos.

Podemos dizer que todos os países do chamado Terceiro Mundo são países que conheceram a fase de economia de exportação de produtos brutos, de produtos de base. Na França se diz que essa era a primeira divisão internacional do trabalho, no final do século XIX e início do século XX, na relação entre os grandes países desenvolvidos, do ponto de vista do capitalismo dominante e o resto do espaço dominado por esses países. Então, esta economia de exportação de produtos brutos em vários países não se organizou em função de um único porto. Mas se organizou em várias regiões, cada uma com um porto. Deu-se assim uma certa divisão do espaço nacional, que era uma divisão ligada à estratégia e ao funcionamento do sistema de exportação de produtos de base, mas havia uma certa divisão funcional porque cada região tinha um porto, a concentração do comércio, os bancos, as regiões interiores como zonas de produção de produtos para a exportação, as zonas de mão de obra, a zona de produção de produtos necessários para a agricultura de exportação, etc.

No Brasil, pode-se ver no Nordeste esta organização de vários portos, com as várias zonas de produção de cana-de-açúcar, na época da cana de açúcar e, atrás destas zonas, áreas de produção de alimentos, áreas de pastagens (bois), etc.

Assim vamos ter o resultado dessa primeira fase que podemos chamar de fase de subdesenvolvimento, de exportação de produtos de base, resultado da primeira organização do espaço ligado à primeira divisão internacional do trabalho. Vamos ter um espaço não com uma região central e várias regiões, ou de economia de produtos brutos ou de economia de subsistência como reserva futura de mão de obra, mas vamos ver uma divisão do espaço, cada divisão com uma subdivisão: do porto, da região central, da zona interior, que vai ser a reprodução do modelo global, mas dentro de uma parte do espaço.

Aí aparece a dificuldade de se utilizar a palavra região, e isso é um problema muito sério da geografia, porque temos uma palavra chave que é "região", mas que vai ser utilizada em várias escalas e vários sentidos.

Podemos chamar de subespaço.

Neste sistema seria o espaço nacional dividido em subespaços e cada subespaço em regiões, no sentido da definição de região central de concentração do setor moderno e de região de drenagem de produtos de base.

Isto vai complicar o modelo porque na fase da industrialização (segunda fase) não há obrigação econômica de que toda indústria fique no porto, na antiga região de exportação, isto porque há outras cidades bem desenvolvidas por razões de estarem um pouco com o papel de exportação. A indústria vai poder se espalhar em várias cidades e vai começar a fazer várias regiões que vão ser mais ou menos na mesma estrutura da chamada região central do modelo da Costa do Marfim.

Geralmente essas cidades têm pouca chance nessa primeira fase da economia de produtos de exportação. 
Algumas são ligadas a uma economia de exportação, umas mais dinâmicas no momento da industrialização, outras, ao contrário, são ligadas a uma cultura de exportação que conhece um fator de regressão ou uma dificuldade econômica. Alguns setores que têm um maior desenvolvimento dos transportes são mais bem adaptados para a localização da indústria.

Então existem diferenças. Essas diferenças que não são fundamentais como na Costa do Marfim, mas que vão fazer que depois de uma primeira localização da indústria em vários pontos do país, uma região tenha uma força maior que as outras para o desenvolvimento industrial e pouco a pouco vai ser uma região de concentração secundária de indústria, fazendo com que pouco a pouco a indústria tenha mais dinamismo na região e cresça mais, tenha mais condições de concorrência em relação aos outros focos industriais e não conheça maior crescimento talvez por perder uma parte do desenvolvimento industrial da primeira fase de localização da indústria.

Então vemos que se vai formar uma região central com todos os sistemas: indústria, terciário superior, etc.

Mas esta região central não vai possuir $90 \%$ da produção industrial, talvez $50 \%, 60 \%, 70 \%$ da indústria e vai haver outras pequenas regiões (sub-regiões centrais) do nível de segunda categoria que vão complicar a organização do espaço, mas sem contradizer o modelo. Mas, ao invés de um modelo perfeito, o modelo é imperfeito. Com uma região central que é a força principal do funcionamento do sistema capitalista do ponto de vista da indústria, terciário, etc., e alguns pontos secundários menores que têm pequenos papéis dentro do funcionamento do setor moderno.

Naturalmente, isto vai complicar um pouco a repartição das regiões de economia primária de reserva de mão-de-obra. Mas é uma complicação do modelo, não é uma negação do modelo.

Outro fator de complicação é o problema das condições de industrialização. Porque no modelo o sistema é o sistema recente de uma industrialização da segunda fase do século XX, quer dizer, uma industrialização numa época de muita concentração de capital bancário e uma industrialização ligada à aplicação de capital exterior, que vem dos países desenvolvidos e por diversas razões se aplica na região, centro antigo de exportação de economia de produtos brutos. Mas em outros países do Terceiro Mundo a história da industrialização é muito mais complicada. A industrialização começou com um esforço da burguesia nacional, que aplicou um capital acumulado à atividade industrial, então é somente depois que vai aparecer a aplicação de capital internacional com a procura de localização ótima, que, em geral, é a localização na região central. Ao contrário, a pri- meira fase da industrialização de uma fase ligada à burguesia nacional pode ser perfeitamente ligada à presença de uma burguesia nacional que tem um pouco de capital e que tem ainda a iniciativa industrial, o que é mais complicado em cidades de porte médio porque havia um pequeno mercado, uma possibilidade de aplicação de capital, então começou o desenvolvimento de algumas indústrias.

Vai ser uma complicação a mais, porque a indústria não vai obedecer aos fatores gerais de localização das multinacionais e das grandes empresas industriais ligadas ao capital internacional, mas vai ter outros fatores de localização bem mais diversificados, ligados a um outro tipo de industrialização e muito mais ligado à evolução interna no sistema econômico do país.

Mesmo assim, nós podemos com um pouco de esforço e um pouco talvez de sistematização - acredito que em quase todos os países do Terceiro Mundo podemos ver que atualmente há disparidades regionais. Só de mapear os critérios que defini no começo é que estas disparidades regionais obedecem, perfeita ou imperfeitamente o modelo: "região central, regiões de economia primária de exportação, regiões de mão-de-obra e região de reserva de espaço para desenvolvimento futuro do capitalismo". Acredito que, quaisquer que sejam as complicações, com um esforço, podemos verificar a realidade desse modelo como explicação das disparidades regionais, quer dizer, de verificar se as disparidades regionais são os resultados da relação básica entre o funcionamento do sistema econômico e a organização do espaço, que é a necessidade do sistema econômico de ter estas disparidades regionais porque é a base do funcionamento do sistema. E por isso, naturalmente, vamos verificar que não é um serviço de planejamento do sistema que vai poder fazer muita coisa para modificar esta organização do espaço. Se a organização do espaço é mesmo o resultado da estrutura da relação entre espaço e sistema, o sistema não tem o poder de modificar muitas coisas dentro dessa organização do espaço. Então aparece uma explicação dessas dificuldades do serviço de planejamento no campo da chamada regionalização, no sentido que defini a palavra, aparecem os fatores de explicação das dificuldades enormes e passar da atenção à realidade duma política de regionalização.

Política das chamadas metrópoles de equilíbrio. Tudo isso são políticas muito difíceis de realizar porque a intenção da política é de modificar de uma maneira importante mesmo, se não for para reequilibrar todo o espaço, é de tentar modificar de uma maneira importante o modelo, a relação básica entre espaço e sistema. Porque descentralização industrial inter-regional, política de criação de metrópoles de equilíbrio no interior 
do espaço é, afinal de contas, uma tentativa de criar outras regiões centrais, até chegar à caricatura de uma política que queria que todo espaço nacional fosse região central, do ponto de vista das características. Se o modelo é exato e se o sistema funcionar como uma região central, isto quer dizer que há periferia. Então, se todo o espaço quer ficar na região central, isto é contraditório com o funcionamento dentro do espaço. E por isso nós podemos verificar que as políticas de descentralização industrial em geral não são bem sucedidas, qualquer que seja o esforço dos governos que gastam muito e muito dinheiro para tentar redistribuir a indústria em outras regiões que não seja a região central.

Ainda mais porque a política de metrópole de equilíbrio é de distribuir a indústria em todas as regiões do país. A intenção é de distribuir o terciário superior e de fazer não a concentração da indústria mas do famoso terciário de comando, e de distribuir o terciário superior em várias cidades bem repartidas no espaço nacional. Isto é quebrar ainda mais a estrutura fundamental de funcionamento do sistema, que é concentração do poder em uma região que vai comandar as outras regiões. Então podemos dizer que estas tentativas de planejamento das disparidades regionais, quando se trata de querer redistribuir no espaço nacional as atividades que são características da região central, são tentativas de pouco sucesso e que a realização é bastante diferente da intenção. Ao contrário, há uma possibilidade de planejamento, que eu não sou pessimista assim, aceitando que o planejamento esteja a serviço do meIhor funcionamento do sistema, porque se a intenção é de quebrar o sistema, vai ser uma contradição com uma atividade de planejamento. Uma atividade de planejamento é uma atividade do poder público, quer dizer, da política do governo com todas as tendências para melhorar o sistema que o governo está representando. Então, quando se trata de um planejamento reformista, que é o único que podemos observar no sistema capitalista (outro planejamento tem de modificar o sistema), pode ser positivo nos problemas de regionalização. É um planejamento que vai aceitar as disparidades regionais do ponto de vista de estruturas como um fator intrínseco do funcionamento do sistema. Não adianta querer quebrar, mas podemos fazer alguma coisa para melhorar o espaço dentro de cada tipo de região. Vamos tomar o exemplo da região central. A região central é a região de concentração da indústria. Não adianta querer impedir esta concentração industrial, quaisquer que sejam os esforços.

Mas podemos racionalizar a localização da indústria nessa região central, porque a multiplicidade de iniciativa no sistema capitalista, que é a relação entre espaço e indústria, é ligada aos agentes econômicos particulares. A multiplicidade de intervenção sobre o espaço faz que o espaço tenha algumas contradições que são: uma concentração demasiadamente importante na cidade principal da região central, com que teria possibilidade numa faixa de 100, 200 e talvez $300 \mathrm{~km}$, de localizar indústrias que teriam as mesmas condições básicas de funcionamento do ponto de vista das economias externas, vantagens comparativas e que teriam outras vantagens de não sofrer da extrema concentração na cidade principal, das dificuldades de circulação, etc.

Então há uma possibilidade de redistribuição da indústria na própria região central e isso é uma evolução espontânea do capitalismo dentro do espaço. Nas regiões centrais mais evoluídas podemos ver que é uma tendência, só que esta tendência espontânea tem muita dificuldade de funcionar. É um planejamento que vai compreender estas necessidades, poder antecipar a evolução que vai ser a evolução do sistema no espaço da região central e preparar as cidades de porte médio a 50, 100 e $200 \mathrm{~km}$ da capital para preparar este novo sistema de localização da indústria. Aí vai estar a localização da fábrica, a direção da empresa vai ficar na grande cidade, mas assim vai haver dentro da região central uma tendência espontânea que aparece nas regiões mais evoluídas, que é a oposição entre a grande cidade, que é mais uma zona de concentração do terciário superior, e a região urbana (raio de 100, 200 quilômetros) que é a região de localização das fábricas, cujas sedes das empresas estão na grande cidade.

$E$, perfeitamente, pode ser preparado num planejamento realista que vai assim fazer uma política da cidade de porte médio, uma política de cidades novas, segundo as condições de uma reutilização da rede urbana anterior, para preparar, racionalizar e antecipar essa evolução da região central dentro do bom funcionamento do sistema capitalista.

Também aceitando que as regiões de economias primárias vão continuar regiões de economia primária, podemos racionalizar um funcionamento e melhorar alguma coisa do funcionamento destas regiões. Pode ser a política de reorganização da rede das pequenas e médias cidades ao serviço da economia agrícola, um melhor funcionamento da comercialização dos produtos agrícolas, etc., várias coisas, que afinal de contas, será também reorganização de rede urbana sem mexer na reorganização da produção. Isto não é mais planejamento e regionalização, é problema de planificação da economia.

Mas sempre guardando a idéia de regionalização, reorganização do espaço regional, podemos montar uma política concreta de reorganização da rede urbana de 
cada região de produção primária para melhorar a relação entre cidade e economia agrícola, a economia primária. Aceitando que elas vão continuar de economia primária, com todas as conseqüências que não podem ser quebradas de desequilíbrios fundamentais do ponto de vista de atividade de rede, etc.

Tem um caráter de tentar reorganizar o espaço nacional quebrando a relação básica entre espaço e sociedade. Estes programas de planejamento são programas que têm um papel na sociedade mas não é um papel de realizar alguma coisa. É um papel de dizer o que é que nós vamos fazer. Quer dizer, uma política de discurso. Em francês se diz: "O discurso e a realização". É dizer porque os desequilíbrios regionais geram algumas tensões sociais. Pouco a pouco as pessoas das regiões periféricas não gostam muito de ver que toda a riqueza vai se acumular na região central e vai haver uma rivalidade, conflitos sociais ligados aos desequilíbrios regionais.

Então o sistema vai se defender, não modificando alguma coisa porque não pode, que é a base do funcionamento parcial do sistema, mas lançando algumas idéias, algumas oposições que vão fazer alguma coisa e o discurso é muito importante numa sociedade. Dizer que o governo vai fazer alguma coisa já é alguma coisa muito importante para diminuir o conflito.

É o papel do planejamento tanto nos países desenvolvidos como nos países subdesenvolvidos. Um papel de montar programas que não vão ser realizados mas que dão o que falar.

Outro aspecto do planejamento regional, de regionalização, é de reorganizar o funcionamento de cada região aceitando a especificidade de cada tipo de região. $E$ isso é o contrário, é um planejamento que vai realizar muitas coisas.

E só para lançar a discussão acho que no Estado de São Paulo já se realizou muita coisa do ponto vista de preparação da concentração industrial. Isto é um planejamento realista. Enquanto que a descentralização inter-regional, quaisquer que sejam os esforços, ainda tem muitas dificuldades para funcionar, a industrialização do Nordeste não modificou basicamente a diferença entre o Nordeste e o Sudeste. Essas são mais ou menos as possibilidades de aplicação neste país bastante complicado. São idéias gerais que tentei explicar a vocês. 